\title{
В.А. Зимина
}

\section{ЭКСПЕРИМЕНТАЛЬНОЕ ИССЛЕДОВАНИЕ СТРУКТУРЫ, УПРУГИХ И ПРОЧНОСТНЫХ ХАРАКТЕРИСТИК ПОРИСТОЙ КОРУНДОВОЙ КЕРАМИКИ ${ }^{1}$}

\begin{abstract}
Представлены результаты экспериментальных исследований структурных, прочностных и упругих свойств образцов из корундовой керамики, полученной при температурах спекания 1400,1500 и $1600{ }^{\circ} \mathrm{C}$. Выполнены механические испытания образцов на трехточечный изгиб. Предел прочности варьировался от 135 до 265 МПа, а модуль упругости находился в диапазоне 58-113 ГПа в зависимости от температуры спекания. Анализ внутренней структуры керамики выявил зависимость пористости, размеров пор и зерен от температуры спекания.
\end{abstract}

Ключевые слова: оксид алюминия, пористая керамика, трехточечный изгиб, микроструктура, РЭМ-анализ, прочность на изгиб, модуль Юнга.

Комбинация таких характеристик керамических материалов как химическая и термическая стабильность, низкая тепло- и электропроводность, высокая прочность, термо- и электроизоляция, высокая твердость, биосовместимость, биоинертность делают их привлекательным материалом для использования в различных сферах деятельности. Например, изделия из керамики на основе оксида алюминия (корундовой керамики) применяются в аэрокосмической, электрической, оборонной, автомобильной, химической, медицинской и других отраслях промышленности [1-4]. Одним из факторов, ограничивающих промышленное применение этой керамики, является ее хрупкость. Проведение испытаний хрупких материалов на одноосное растяжение считаются весьма трудно реализуемыми, так как при испытаниях возникают трудности, связанные со сложностью крепления образца в испытательной машине. Поэтому для оценки прочности при растяжении керамики, как и других хрупких материалов, широко применяются косвенные методы. Наиболее распространенными из таких методов считаются испытания на трехточечный изгиб и метод диаметрального сжатия цилиндрических образцов (бразильский тест) [5-10].

Хорошо известно, что на прочность керамики влияет ее структура, а именно, фазовый состав, наличие микродефектов, размер и форма пор и зерен. В зависимости от технологии и условий изготовления керамических материалов, они могут обладать структурой с различным содержанием и конфигурацией пор, следовательно, различными физико-механическими свойствами. Также в ней могут присутствовать поверхностные и внутренние дефекты, которые локально увеличивают концентрацию напряжений, что приводит к распространению трещин в керамике и впоследствии выходу из строя изделий в процессе эксплуатации.

На сегодняшний день существует достаточно много экспериментальных работ, по изучению механических свойств, внутренней структуры корундовой керамики,

\footnotetext{
1 Работа выполнена в рамках государственного задания ИФПМ СО РАН, проект III.23.2.3 и при поддержке Программы повышения конкурентоспособности ТГУ.
} 
а также связи между ними, но не все аспекты данной проблемы до конца выяснены. Потребность в этих материалах оставляет задачу определения влияния структуры пористых керамик на упругие и прочностные свойства актуальной. Соответственно определение прочности и характера разрушения пористых керамик, полученных в разных условиях и обладающих разной структурой, с помощью экспериментальных исследований является перспективным направлением.

Целью настоящей работы является исследование структуры и оценка упругих и прочностных характеристик образцов из пористой корундовой керамики, полученной при различных температурах спекания.

\section{Материалы, методы и оборудование}

Образцы были получены методом шликерного литья из технически чистого порошка $\mathrm{Al}_{2} \mathrm{O}_{3}$ и спекались изотермически с выдержкой 1 ч при трех разных температурах $1400,1500,1600{ }^{\circ} \mathrm{C}$. После этого была измерена пористость полученных образцов. Вычисление пористости проводилось на основе измеренных значений массы и объема образцов. Объем определяли геометрическим способом, с последующим расчетом плотности. Массу - с помощью лабораторных весов AB-120-01.

Пористость рассчитывалась согласно формуле

$$
\Pi=100 \%-\frac{\rho}{\rho_{\text {плотн }}} 100 \%,
$$

где П - пористость спеченного образца, \%; $\rho$ - плотность спеченного образца; $\rho_{\text {плотн }}=3.97$ г $/ \mathrm{cm}^{3}$ - плотность беспористого $\mathrm{Al}_{2} \mathrm{O}_{3}[11]$.

Для определения механических свойств спеченных образцов был применен метод трехточечного изгиба. Согласно данному способу нагружения, часть образца испытывает сжимающие нагрузки, а другая - растягивающие напряжения, наиболее опасные для пористых керамик. Эксперимент проводился на универсальной испытательной машине Instron 1185 со скоростью нагружения 0.1 мм/мин. Были испытаны по 5 образцов для каждого значения температуры спекания. Расстояние между опорами составляло 30 мм. Схема нагружения образца и фотография реального образца в испытательной машине в ходе эксперимента представлены на рис. 1. Значения прочности на изгиб $(\sigma)$ и модуля упругости $(E)$ керамических образцов рассчитывались согласно формулам, представленным в $[12,13]$ :

$$
\begin{gathered}
\sigma=\frac{3 P l}{2 b h^{2}} ; \\
E=\frac{\left(F_{2}-F_{1}\right) l^{3}}{4\left(l_{2}-l_{1}\right) b h^{3}},
\end{gathered}
$$

где $P$ - максимальная нагрузка, установленная при испытании образца, $\mathrm{H} ; l$ - расстояние между нижними опорами (база $l=30$ мм), мм; $b$ - ширина образца, мм; $h$ - средняя толщина образца, мм; $F_{1}, F_{2}$ - усилия на линейном участке диаграммы нагружения, $\mathrm{H} ; l_{1}, l_{2}$ - прогибы, соответствующие нагрузкам $F_{1}$ и $F_{2}$, которые определялись из диаграмм нагружения.

Исследование микроструктуры керамических образцов проводилось с помощью растрового электронного микроскопа Vega 3 LMU, оснащенного программным обеспечением AZtec для обработки и анализа изображений. 

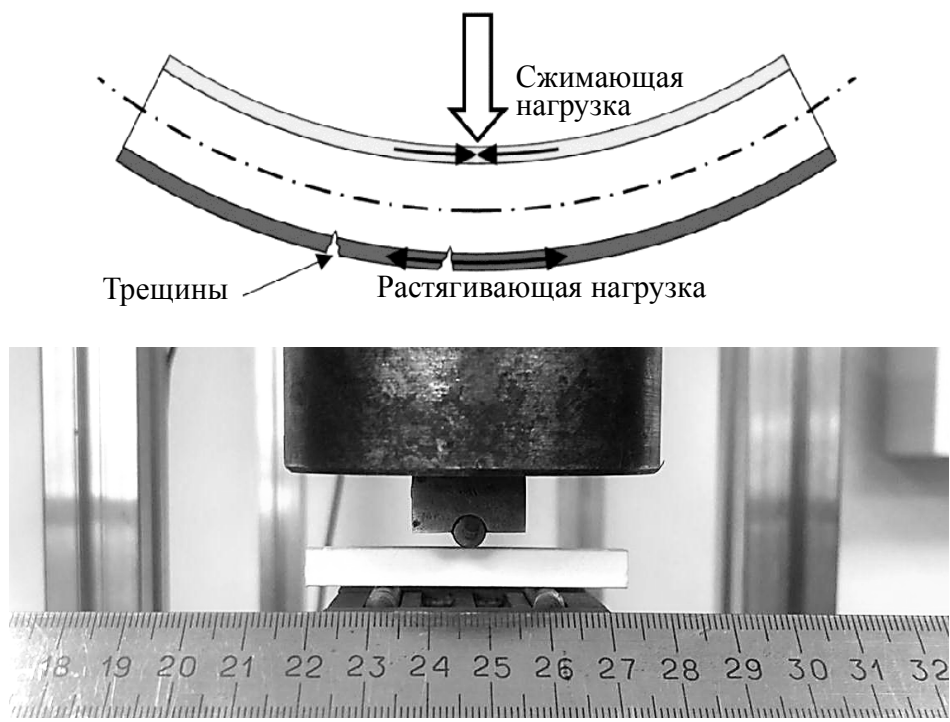

Рис. 1. Схематическое представление трехточечного изгиба образца $(a)$, реальный эксперимент $(b)$

Fig. 1. (a) Schematic representation of a three-point bending of the sample; (b) a natural experiment

\section{Результаты и обсуждение}

На рис. 2 представлены фотографии поверхности образцов корундовой керамики после травления для каждого значения температуры спекания. На этих фотографиях хорошо видна структура керамических образцов. Анализ этих структур позволил выявить морфологические особенности порового пространства и размеры таких структурных элементов, как зерна и поры.
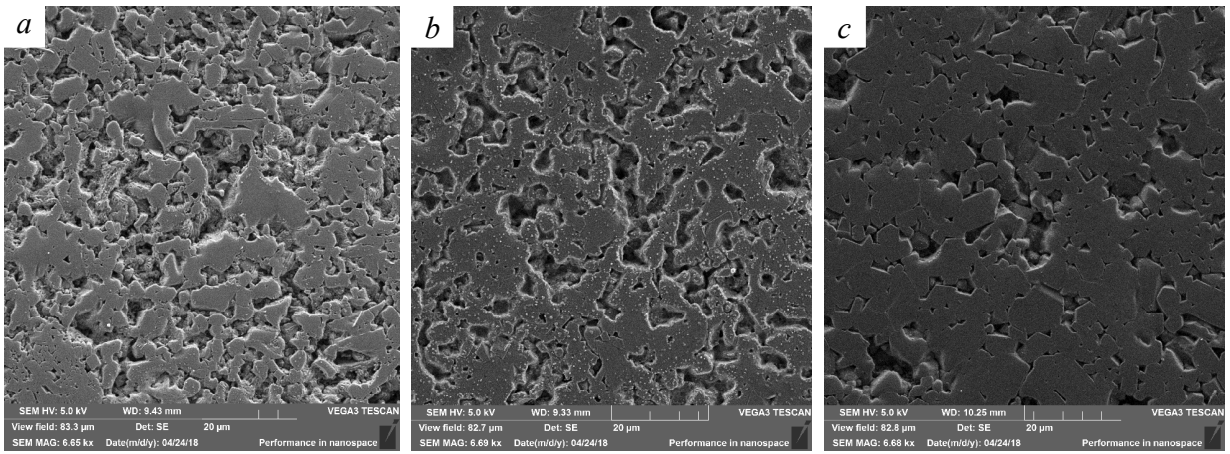

Рис. 2. Снимки поверхности образцов корундовой керамики после травления, полученные при помощи растрового электронного микроскопа. Температура спекания образцов: $1400(a), 1500(b)$ и $1600{ }^{\circ} \mathrm{C}(c)$

Fig. 2. The images of the surface of alumina ceramic samples after etching obtained using a scanning electron microscope. A sintering temperature for the samples is of: $(a) 1400,(b) 1500$, and (c) $1600{ }^{\circ} \mathrm{C}$ 
На снимках структур видно, что поры имеют сложное извилистое строение. При температуре спекания $1400{ }^{\circ} \mathrm{C}$ большинство пор сообщаются друг с другом. С ростом температуры спекания количество открытой пористости уменьшается, а закрытой пористости - увеличивается.

Анализируя результаты исследования распределения пор по размерам (рис. 3, слева), можно отметить, что все распределения имеют унимодальный характер и средний размер пор для температур спекания от 1400 до $1600^{\circ} \mathrm{C}$ практически не меняется. Ожидалось, что средний размер пор должен уменьшаться с ростом температуры спекания, однако этого не наблюдается. Это может быть обусловлено большим значением среднеквадратичных отклонений результатов измерений.

Анализ диаграмм распределения зерен по размерам (рис. 3, справа) в образцах, спеченных при разных температурах, показывает, что распределения являются также унимодальными. Средний размер зерен для всех температур спекания составляет 2-3 мкм.

Среднее значение пористости образцов, спеченных при температурах 1400, 1500 и $1600{ }^{\circ} \mathrm{C}$ составило 33, 26 и $17 \%$ соответственно.
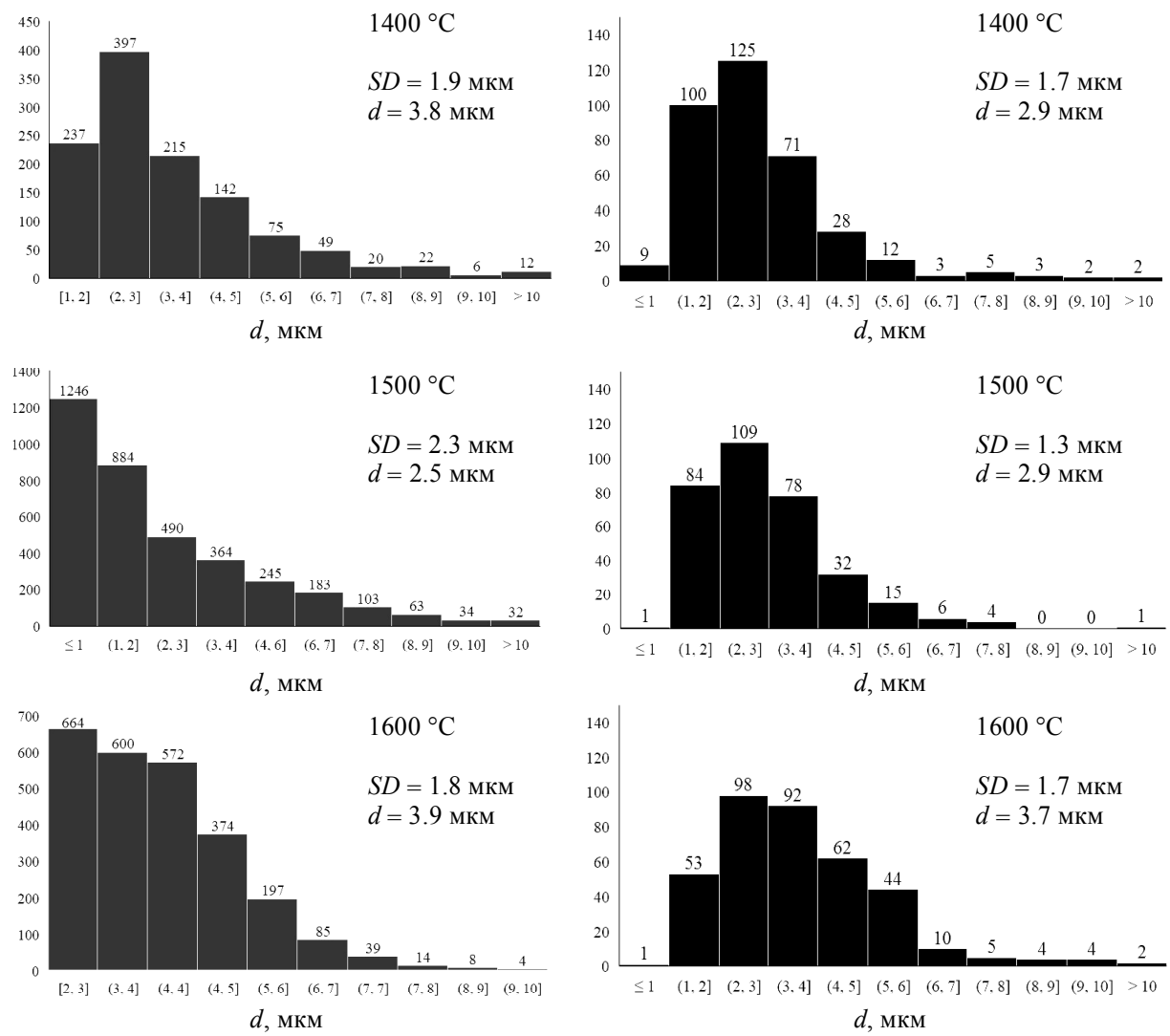

Рис. 3. Распределения пор (слева) и зерен (справа) по размерам в керамических образцах различной температуры спекания

Fig. 3. The size distributions of pores (on the left) and grains (on the right) for ceramic samples sintered at different temperatures 
По результатам испытаний на трехточечный изгиб были построены кривые нагружения и рассчитаны пределы прочности на изгиб и модули упругости образцов для различных значений пористости. На рис. 4, $a$ изображены по одной кривой нагружения для каждого значения температуры спекания. На рис. $4, b$ и $c$ представлены зависимости пористости от температуры спекания образцов и прочности от пористости образцов. Полученные в результате обработки измерений физикомеханические характеристики спеченных образцов приведены в таблице.
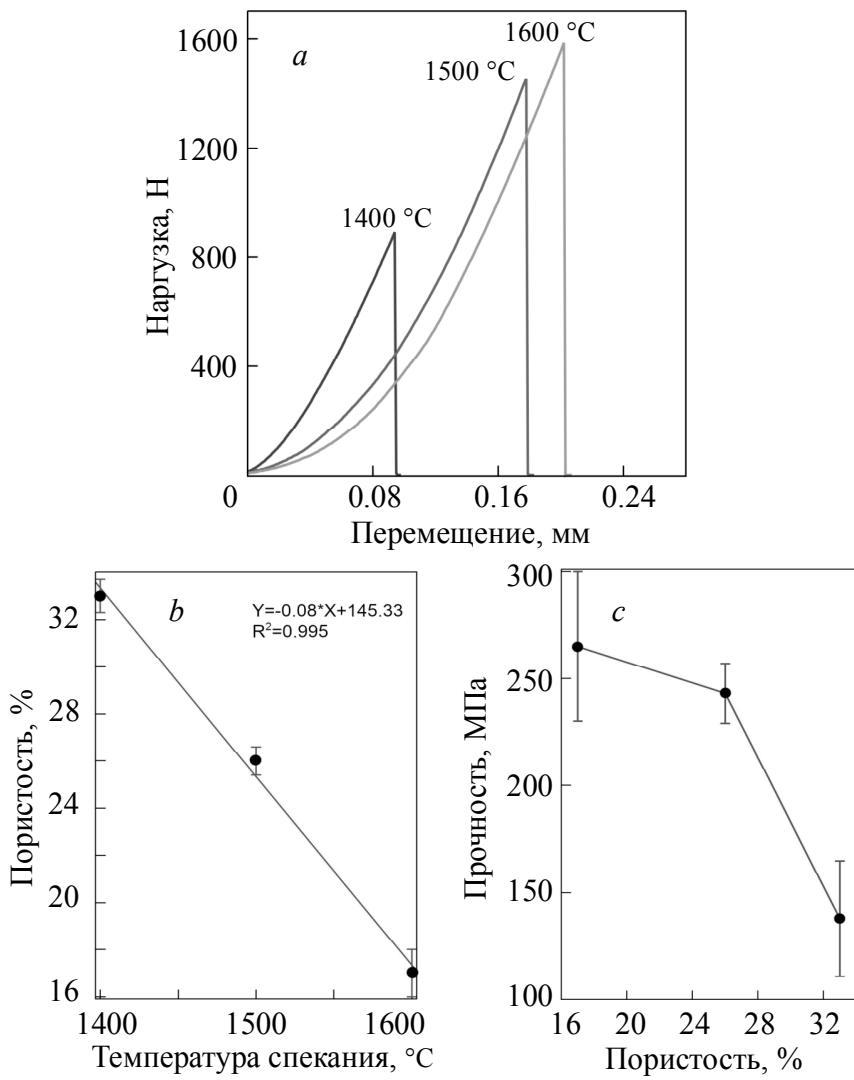

Рис. 4. Экспериментальные кривые нагружения (a), зависимость пористости от температуры спекания образцов $(b)$ и зависимость прочности от пористости образцов $(c)$

Fig. 4. (a) Experimental load-displacement curves, $(b)$ dependence of the porosity on the sintering temperature of the samples, and (c) dependence of the strength on the porosity of the samples

Характеристики образцов корундовой керамики

\begin{tabular}{|c|c|c|c|c|c|c|}
\hline $\begin{array}{c}\text { Температура } \\
\text { спекания, } \\
{ }^{\circ} \mathrm{C}\end{array}$ & $\begin{array}{c}\text { Масса, } \\
\Gamma\end{array}$ & $\begin{array}{c}\text { Объем, } \\
\text { см}^{3}\end{array}$ & $\begin{array}{c}\text { Плотность, } \\
\Gamma^{2} \text { см }^{3}\end{array}$ & $\begin{array}{c}\text { Порис- } \\
\text { тость, } \\
\%\end{array}$ & $\begin{array}{c}\text { Предел } \\
\text { прочности } \\
\sigma, \text { МПа }\end{array}$ & $\begin{array}{c}\text { Модуль } \\
\text { упругости } \\
E, \text { ГПа }\end{array}$ \\
\hline 1400 & $6.393 \pm 0.014$ & $2.419 \pm 0.019$ & $2.642 \pm 0.028$ & $33 \pm 0.7$ & $138 \pm 27$ & $58 \pm 7$ \\
\hline 1500 & $6.399 \pm 0.006$ & $2.174 \pm 0.016$ & $2.944 \pm 0.021$ & $26 \pm 0.6$ & $243 \pm 14$ & $80 \pm 13$ \\
\hline 1600 & $6.395 \pm 0.017$ & $1.956 \pm 0.018$ & $3.27 \pm 0.036$ & $17 \pm 1$ & $265 \pm 35$ & $173 \pm 16$ \\
\hline
\end{tabular}


Анализируя результаты, представленные в таблице, можно отметить, что при повышении температуры спекания наблюдается усадка образцов и соответственно уменьшение их пористости. Пористость образцов линейно уменьшается при увеличении температуры спекания примерно на 7-9 \% на каждые $100{ }^{\circ} \mathrm{C}$ (рис. $4, b$ ). С уменьшением значения пористости в образцах увеличивается предел прочности и модуль упругости, причем эти зависимости нелинейные, что согласуется с теоретическими и экспериментальными данными других авторов [14-16].

В целом можно отметить, что структура образцов оказывает существенное влияние на упругие и прочностные свойства керамических образцов. Сама поровая структура не является периодической, а имеет случайный характер. В этом случае для анализа прочностных зависимостей применяют статистические методы. Для описания статистического поведения механических свойств многих материалов, в том числе и керамик, широко используется анализ Вейбулла [17-20]. Поэтому в работе статистический анализ прочности исследуемых образцов был проведен с помощью модели Вейбулла [17].

На рис. 5 представлены графики Вейбулла для прочности керамических образцов, спеченных при различных температурах. Видно, что данные предела прочности для температур спекания 1500 и $1600{ }^{\circ} \mathrm{C}$ хорошо описываются распределением Вейбулла, а при температуре спекания $1400^{\circ} \mathrm{C}$ отмечается большее отклонение экспериментальных точек от графика Вейбулла. Форма распределения Вейбулла характеризуется значением модуля Вейбулла. Чем больше его величина, тем меньше разброс в экспериментальных значениях, соответственно одно значение прочности может служить хорошим описанием всей выборки. В данной работе максимальное значение модуля Вейбулла составило 22 для образцов, спеченных при температуре $1500{ }^{\circ} \mathrm{C}$, а для образцов, спеченных при температурах 1400 и $1600{ }^{\circ} \mathrm{C}$, они сравнимы (5.8 и 6.7) и соответствуют данным для корундовой керамики, приведенным в статье [18].

\section{Заключение}

В результате проведенного исследования, показано, что с увеличением температуры спекания на $100{ }^{\circ} \mathrm{C}$ значение пористости корундовых керамических образцов уменьшается на 7-9\%. Анализ структуры показал, что средние размеры пор практически не меняются от температуры спекания, а размеры зерен в керамике увеличиваются с ее ростом.

Показано, что прочность и модуль упругости нелинейно возрастают с увеличением температуры спекания. При этом разброс их значений достаточно велик и обусловлен присутствием структурных неоднородностей в образцах и их влиянием на механические характеристики. Следует отметить, что оценка механических свойств производилась в зависимости только от значений общей пористости. Как показал проведенный анализ, этого недостаточно для наиболее полного описания механического поведения керамических образцов. Возможно, нужно учитывать другие характеристики поровой структуры, такие, как форма пор, связность и прочее.

Проведенный статистический анализ полученных экспериментальных данных о прочности при изгибе исследуемых образцов показал, что они хорошо описываются распределением Вейбулла. Максимальное значение модуля Вейбулла получено для температуры спекания $1500{ }^{\circ} \mathrm{C}$. 

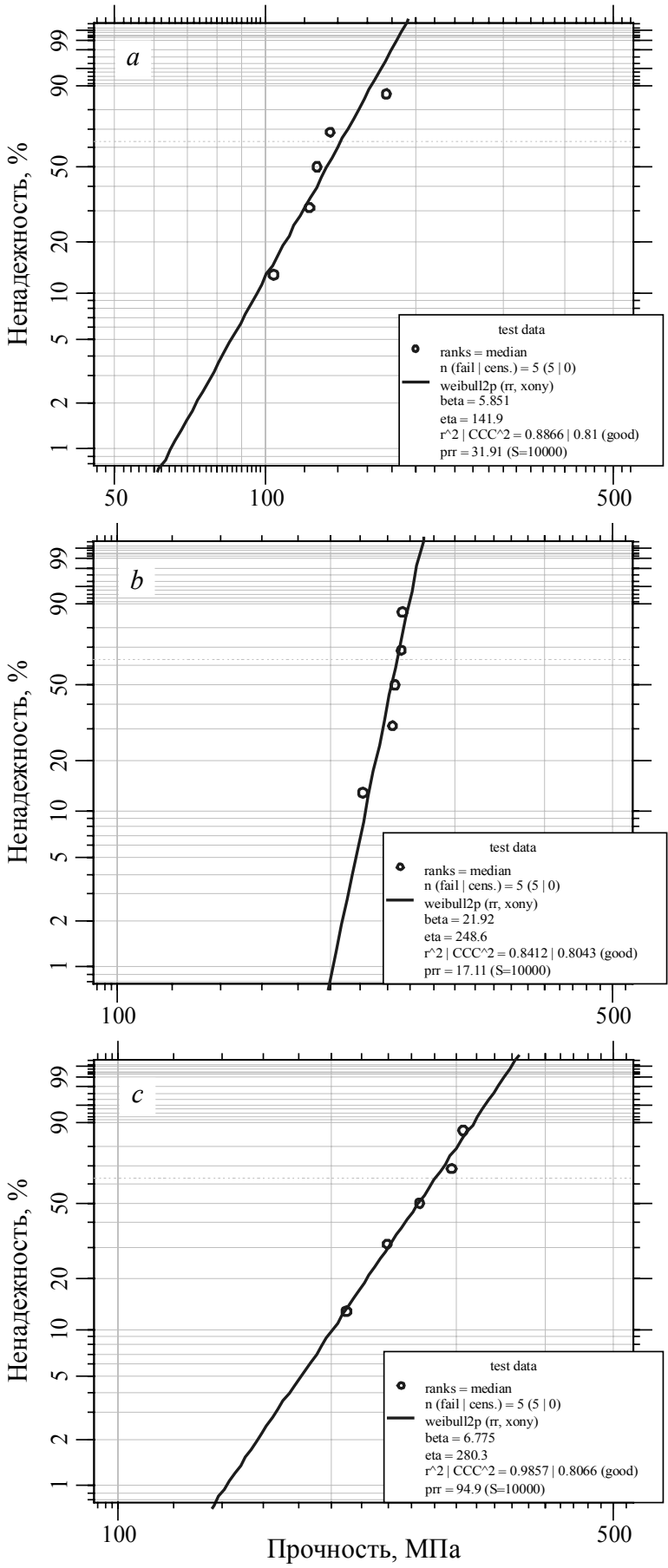

Рис. 5. Анализ Вейбулла для керамических образцов с различной температурой спекания: $1400(a), 1500(b)$ и $1600{ }^{\circ} \mathrm{C}(c)$ Fig. 5. Weibull analysis for ceramic samples with different sintering temperatures: (a) 1400, (b) 1500 , and (c) $1600{ }^{\circ} \mathrm{C}$ 
Автор выражает благодарность своему научному руководителю И.Ю. Смолину за обсуждение полученных результатов и за полезные замечания при написании статьи, а также А.С. Кулькову за участие в экспериментах и проведение анализа внутренней структуры образцов.

\section{ЛИТЕРАТУРА}

1. Okada A. Ceramic technologies for automotive industry: current status and perspectives // Mater. Sci. Eng. B. 2009. V. 161. P. 182-187. DOI: 10.1016/j.mseb.2008.11.017.

2. Sequeira S., Fernandes M.H., Neves N., Almeida M.M. Development and characterization of zirconia-alumina composites for orthopedic implants // Ceram. Int. 2017. V. 43. P. 693-703. DOI: $10.1016 /$ j.ceramint.2016.09.216.

3. Лукин Е. С., Макаров Н.А., Козлов А.И., Попова Н.А., Ануфриева Е.В., Вартанян М.А., Козлов И.А., Сафина М.Н., Лемешев Д.О., Горелик Е.И. Оксидная керамика нового поколения и области ее применения // Стекло и керамика. 2008. №10. С. 27-31.

4. Красный Б.Л., Тарасовский В.П., Красный А.Б., Кутейникова А.Л. Свойства пористой проницаемой керамики на основе монофракционных порошков корунда и нанодисперсного связующего // Стекло и керамика. 2009. № 6. С. 18-21.

5. Жолудев Д.С., Григорьев С.С., Панфилов П.Е., Зайцев Д.В. Обоснование использования керамики на основе оксида алюминия с помощью изучения её механических свойств // Современные проблемы науки и образования. 2014. № 3. С. 520.

6. Carter C.B., Norton M.G. Ceramic materials: science and engineering. New York: Springer, 2007. $716 \mathrm{p}$.

7. Basu B., Balani K. Advanced Structural Ceramics. Hoboken: John Wiley \& Sons, Inc., 2011. $512 \mathrm{p}$.

8. Севостьянова И.Н. Саблина Т.Ю. Горбатенко В.В., Кульков С.Н. Локализация деформации при диаметральном сжатии керамики $\mathrm{ZrO}_{2}\left(\mathrm{Y}_{2} \mathrm{O}_{3}\right) / /$ Письма в ЖТФ. 2019. Т. 45. Вып. 18. C.40-43. DOI: 10.21883/PJTF.2019.18.48237.17766.

9. Johnstone C., Ruiz C. Dynamic testing of ceramics under tensile stress // Int. J. Solids Struct. 1995. V. 32 (17-18). P. 2647-2656. DOI: 10.1016/0020-7683(94)00287-7.

10. Sheikh M. Z., Wang Z., Du B., Suo T., Li Y., Zhou F., Wang Y., Dar U. A., Gao G., Wang $Y$. Static and dynamic Brazilian disk tests for mechanical characterization of annealed and chemically strengthened glass // Ceram. Int. 2019. V. 45. P. 7931-7944. DOI: 10.1016/j.ceramint.2019.01.106.

11. Properties: Alumina - Aluminium Oxide - Al2O3 - A Refractory Ceramic Oxide. URL: https://www.azom.com/properties.aspx?ArticleID = 52 (дата обращения: 13.04.2020).

12. ГОСТ Р 57749-2017 (ИСО 17138:2014) Композиты керамические. Метод испытания на изгиб при нормальной температуре, М.: Стандартинформ, 2017. $11 \mathrm{c.}$

13. ГОСТ 9550-81 Пластмассы. Методы определения модуля упругости при растяжении, сжатии и изгибе. М.: ИПК Изд-во стандартов, 2004. 6 с.

14. Григорьев М.В., Савченко Н.Л., Буякова С.П., Кульков С.Н. Неупругое поведение при сжатии керамики с иерархической поровой структурой // Письма в ЖТФ. 2017. Т. 43. Вып. 15. C. 79-86. DOI: 10.21883/PJTF.2017.15.44874.16652.

15. Смолин И.Ю., Еремин М.О., Макаров П.В., Буякова С.П., Кульков С.Н., Евтушенко Е.П. Численное моделирование механического поведения модельных хрупких пористых материалов на мезоуровне // Вестник Томского государственного университета. Математика и механика. 2013. № 5(25). С. 78-90.

16. Savchenko N., Sevostyanova I., Sablina T., Gömze L., Kulkov S. The influence of porosity on the elasticity and strength of alumina and zirconia ceramics // AIP Conference Proceedings. 2014. V. 1623 (1). P. 547-550. DOI: 10.1063/1.4899003.

17. Weibull W. A statistical distribution function of wide applicability // J. Appl. Mech. 1951. V. 18. P. 293-305.

18. Le Corre V., Brusselle-Dupend N., Moreaud M. Numerical modeling of the effective ductile damage of macroporous alumina // Mech. Mater. 2017. V. 114. P. 161-171. DOI: 10.1016/j.mechmat.2017.08.002. 
19. Ćurković L., Bakić A., Kodvanj J., Haramina T. Flexural strength of alumina ceramics: Weibull analysis // Transactions of Famena. 2010. V. 34(1). P. 13-19.

20. Meille S., Lombardi M., Chevalier J., Montanaro L. Mechanical properties of porous ceramics in compression: On the transition between elastic, brittle, and cellular behavior // J. Eur. Ceram. Soc. 2012. V. 32. P. 3959-3967. DOI: 10.1016/j.jeurceramsoc.2012.05.006.

Статья поступила 10.06.2020 г.

Zimina V.A. (2020) EXPERIMENTAL INVESTIGATION OF THE STRUCTURE, ELASTIC, AND STRENGTH CHARACTERISTICS OF POROUS CORUNDUM CERAMICS. Vestnik Tomskogo gosudarstvennogo universiteta. Matematika i mekhanika [Tomsk State University Journal of Mathematics and Mechanics]. 67. pp. 117-126

DOI $10.17223 / 19988621 / 67 / 11$

Keywords: alumina, porous ceramics, three-point bending, microstructure, SEM analysis, flexural strength, Young's modulus.

This paper aims to investigate the internal structure and to evaluate the elastic and strength characteristics of the corundum ceramic samples sintered at different temperatures. The average value of porosity of the sintered samples at the temperatures of 1400,1500 , and $1600{ }^{\circ} \mathrm{C}$ is 33,26 , and $17 \%$, respectively. Mechanical tests of the ceramic samples are performed using the threepoint bending method. The ultimate bending strength varies from 135 to $265 \mathrm{MPa}$ in the studied sintering temperature range. The elastic moduli of the sintered samples are found to be in the range of $58-113 \mathrm{GPa}$. An analysis of the ceramic samples' microstructure is performed using a scanning electron microscope. The dependence of the porosity, pore size, and grain size on the sintering temperature is indicated. The values of strength and elastic modulus of the samples increase nonlinearly with rising sintering temperature in the experiment. Statistical behavior of mechanical properties of the ceramic samples is described using the Weibull analysis. The strength data for the sintering temperatures of 1500 and $1600{ }^{\circ} \mathrm{C}$ are well described by the Weibull distribution, and the strength values for a sintering temperature of $1400{ }^{\circ} \mathrm{C}$ are described with a significant scatter.

Valentina A. ZIMINA (Institute of Strength Physics and Materials Science SB RAS, National Research Tomsk State University, Tomsk, Russian Federation). E-mail: mikushina_93@mail.ru

Financial support. The work was performed according to the Government research assignment for ISPMS SB RAS, project No. III.23.2.3 and with the support of the Tomsk State University Competitiveness Improvement Program.

\section{REFERENCES}

1. Okada A. (2009) Ceramic technologies for automotive industry: current status and perspectives. Materials Science and Engineering: B. 161. pp. 182-187. DOI: 10.1016/j.mseb. 2008.11.017.

2. Sequeira S., Fernandes M.H., Neves N., Almeida M.M. (2017) Development and characterization of zirconia-alumina composites for orthopedic implants. Ceramics International. 43. pp. 693-703. DOI: 10.1016/j.ceramint.2016.09.216.

3. Lukin E.S., Makarov N.A., Kozlov A.I., Popova N.A., Anufrieva E.V., Vartanyan M.A., Kozlov I.A., Safina M.N.,. Lemeshev D.O., Gorelik E.I. (2008) Oxide ceramics of the new generation and areas of application. Glass and Ceramics. 65(9). pp. 348-352. DOI: 10.1007/s10717-009-9085-y.

4. Krasnyi B.L., Tarasovskii V.P., Krasnyi A.B., Kuteinikova A.L. (2009) Properties of porous permeable ceramic based on monofractional corundum powders and nanodispersed binder. Glass and Ceramics. 66. pp. 212-215. DOI: 10.1007/s10717-009-9164-0.

5. Zholudev D.S., Grigoriev S.S., Panfilov P.E., Zaytsev D.V. (2014) Obosnovanie ispol'zovaniya keramiki na osnove oksida alyuminiya s pomoshch'yu izucheniya ee 
mekhanicheskikh svoystv [Rationale for use of ceramics based on alumina by studying its mechanical properties]. Sovremennye problemy nauki i obrazovaniya-Modern Problems of Science and Education. 3. p. 520.

6. Carter C.B., Norton M.G. (2007) Ceramic Materials: Science and Engineering. New York: Springer.

7. Basu B., Balani K. (2011) Advanced Structural Ceramics. Hoboken: John Wiley \& Sons, Inc.

8. Sevostyanova I.N., Sablina T.Y., Gorbatenko V.V., Kulkov S.N. (2019) Strain localization during diametral compression of $\mathrm{ZrO}_{2}(\mathrm{Y} 2 \mathrm{O} 3)$. Technical Physics Letters. 45. pp. 943-946. DOI: $10.1134 / \mathrm{S} 1063785019090281$.

9. Johnstone C., Ruiz C. (1995) Dynamic testing of ceramics under tensile stress. International Journal of Solids and Structures. 17-18. pp. 2647-2656. DOI: 10.1016/0020-7683(94)00287-7.

10. Sheikh M.Z., Wang Z., Du B., Suo T., Li Y., Zhou F., Wang Y., Dar U.A., Gao G., Wang Y. (2019) Static and dynamic Brazilian disk tests for mechanical characterization of annealed and chemically strengthened glass. Ceramics International. 45. pp. 7931-7944. DOI: 10.1016/j.ceramint.2019.01.106.

11. Properties: Alumina - Aluminium Oxide $-\mathrm{Al}_{2} \mathrm{O}_{3}-\mathrm{A}$ Refractory Ceramic Oxide. Access mode: https://www.azom.com/properties.aspx?ArticleID $=52$.

12. ISO 17138:2014 (2014) Fine ceramics (advanced ceramics, advanced technical ceramics) Mechanical properties of ceramic composites at room temperature - Determination of flexural strength.

13. GOST 9550-81 (2004) Plastmassy. Metody dlya opredeleniya modulya uprugosti pri rastyazhenii, szhatii $i$ izgibe [Plastics. Methods for determination of elasticity modulus at strength, compression, and bending].

14. Grigor'ev M.V., Savchenko N.L., Buyakova S.P., Kul'kov S.N. (2017) Inelastic behavior of ceramics with hierarchical pore structure under compression. Technical Physics Letters. 43. pp. 723-726. DOI: 10.1134/S1063785017080089.

15. Smolin I.Yu., Eremin M.O., Makarov P.V., Buyakova S.P., Kulkov S.N., Evtushenko E.P. (2013) Chislennoe modelirovanie mekhanicheskogo povedeniya model'nykh khrupkikh poristykh materialov na mezourovne [Numerical modeling of mechanical behaviour of model brittle porous materials at mesoscale]. Vestnik Tomskogo gosudarstvennogo universiteta. Matematika i mekhanika - Tomsk State University Journal of Mathematics and Mechanics. 5(25). pp. 78-90.

16. Savchenko N., Sevostyanova I., Sablina T., Gömze L., Kulkov S. (2014) The influence of porosity on the elasticity and strength of alumina and zirconia ceramics. AIP Conference Proceedings. 1623(1). pp. 547-550. DOI: 10.1063/1.4899003.

17. Weibull W.A (1951) Statistical distribution function of wide applicability. Journal of Applied Mechanics. 18. pp. 293-305.

18. Le Corre V., Brusselle-Dupend N., Moreaud M. (2017) Numerical modeling of the effective ductile damage of macroporous alumina. Mechanics of Materials. 114. pp. 161-171. DOI: 10.1016/j.mechmat.2017.08.002.

19. Ćurković L., Bakić A., Kodvanj J., Haramina T. (2010) Flexural strength of alumina ceramics: Weibull analysis. Transactions of Famena. 34(1). pp. 13-19.

20. Meille S., Lombardi M., Chevalier J., Montanaro L. (2012) Mechanical properties of porous ceramics in compression: On the transition between elastic, brittle, and cellular behavior. Journal of the European Ceramic Society. 32. pp. 3959-3967. DOI: 10.1016/j.jeurceramsoc. 2012.05.006.

Received: June 10, 2020 